\title{
Embedded Temperature Sensor Array to Measure Distributed Heat Flux for Water Jet Cooling
}

\author{
Hyo Chang Cho, Bo Wang, Sung Hoon Kim, Jeung Sang Go \\ School of Mechanical Engineering /Pusan National University \\ Busandaehak-ro 63beon-gil 2, Geumjeong-gu, Busan, Republic of Korea \\ chocho@pusan.ac.kr; wangbomems@pusan.ac.kr; shkim91@pusan.ac.kr; micros@ pusan.ac.kr
}

\begin{abstract}
In order to design cooling systems, it is necessary to directly measure the cooling performance such as temperature and heat flux. However it has limitation of the sensor installation due to the narrow measurement space and also high operating temperature. In this limitation, the temperature has measured inlet and outlet. The surface temperature has measured indirectly and heat flux is predicted. This indirect method is needed accuracy of the sensor position and additional work such as development of a post processing calculation code in accordance with the shape are required.

In this paper, we propose a method of directly measurement of the surface temperature and the heat flux. The temperature sensor fabricated close to the surface in order to improve the accuracy of the sensor for measuring the surface temperature and the heat flux. The fabricated thermocouple temperature sensor has applied on the surface temperature measurement experiment in the impinging jet cooling. To prevent sensor and the substrate were damaged due to thermal stress, a method with the ductility metal block substrate which embedded the sensor close to the surface has been proposed. The measured temperature was converted into the heat flux by the 1-D transient method. The metal block embedded with the sensors measured the distribution of the surface heat flux for water impinging jet at an initial temperature of $600{ }^{\circ} \mathrm{C}$ and the maximum heat flux was $4 \mathrm{MW} / \mathrm{m}^{2}$. This measurement technique can be applied to the performance evaluation of steel manufacturing process and heat exchangers.
\end{abstract}

Keywords: Embedded Temperature Sensor Array, Surface Heat Flux, Surface Temperature, Water Impinging Jet Cooling, 1-D Transient Conduction Method.

\section{Introduction}

Impinging jet cooling is used to achieve an enhanced heat transfer coefficient. Especially, if the temperature of a cooling target is higher than the saturation temperature of a coolant, boiling occurs at the liquid-solid interface. In this case, latent heat and buoyancy-driven flow effects lead to a much larger heat transfer coefficient than convection heat transfer without phase change [1]. However, the thermal performance evaluation for two phase cooling is difficult by using conventional sensors due to disturbance of flow and boiling bubbles and vapours. In this limitation, the surface temperature has measured indirectly and heat flux is predicted [2]. In addition, a numerical approach such as the inverse heat conduction method requires precise sensor installation. When the temperature of a target specimen is very high, the selection of a temperature sensor is even further limited. Therefore, in this paper, surface temperature sensors on a surface and embedded temperature sensors in a steel block were developed for the direct measurement of thermal performance including temperature and heat flux on the surface in two phase cooling at a high temperature. Also, the possibility of using these sensors to measure temperature in the two phase cooling process was assessed by applying a water impinging jet to the specimen under the high temperature condition. The heat flux was measured from this temperature measurement by solving the 1-D heat conduction method. These studies will help to measure the heat transfer rate more accurately during the two phase cooling process.

\section{Design and Fabrication of Embedded Temperature Sensor Array in a Steel Block 2.1. Design of Embedded Temperature Sensor Array}

It was experimentally confirmed that the surface $\mathrm{T} / \mathrm{C}$ sensor is difficult to apply the surface heat flux measurement under the water impinging jet cooling. Due to the quartz plate and surface T/C array were damaged by thermal shock from water impingement as shown in Fig 1. Thus, an embedded temperature sensor array in a steel block was suggested to solve the 
defects of the surface temperature sensor for the measurement of the surface heat flux at high temperature with the phase changes of coolant.

In this reason, we designed of the embedded temperature sensor array in the steel block to avoid direct contact of water to the surface sensors which, were damaged by thermal shock under water impinging jet cooling like as quartz plate and surface T/C array due to the thermal expansion coefficient difference. And also, it had to determine a temperature sensor type, a quantity and a dimension of sensor, and an electrical insulation method between sensor and steel block.

The steel has a high melting point, good ductility, and high electrical conductivity for the thermal shock by water impinging jet. And also, the specimen can heat uniformly by using the high frequency induction heating system Thus, SUS 304 was determined in order to measure the heat flux distribution in the high temperature. The temperature sensor for embedding to steel block was determined the K-type T/C. Also, the depths of the sensors were determined at 250 and 550 $\mu \mathrm{m}$. Seven sensors were to be arranged in the radial direction with $6 \mathrm{~mm}$ intervals.
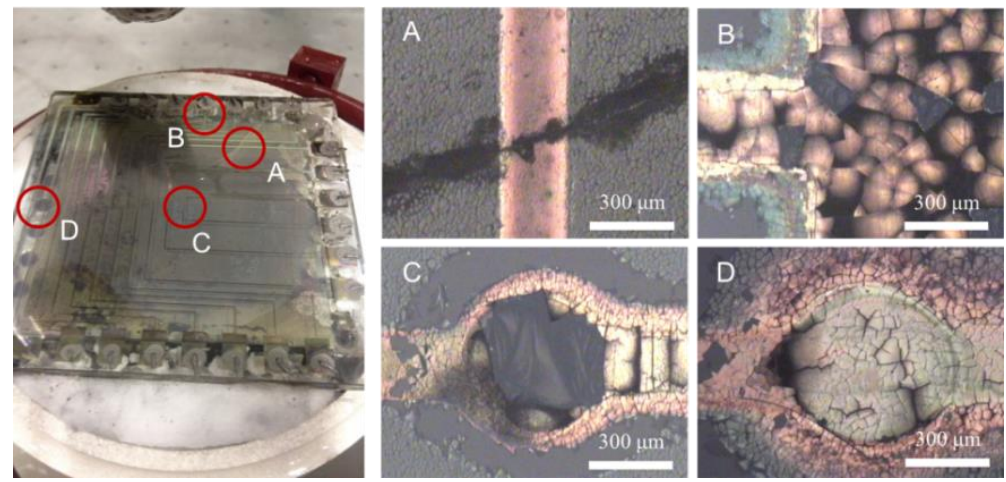

Fig. 1: Damage of the T/C sensors array and quartz substrate (A: Substrate crack, B: Electrode failure, C: T/C junction delamination Omm away, D: T/C junction delamination $40.5 \mathrm{~mm}$ away).

\subsection{Fabrication of Embedded Temperature Sensor Array}

Fig. 2 shows a special fabrication process of the embedded temperature sensor array in the steel block. The fabrication procedure is like as following: First over all, the electrical insulation material was filled to microchannel on base block, and a protruded electrical insulation material over the microchannel in the base block was polished. In a second step, a masking without microchannels for the electrical insulation material to be filled only in the microchannels, and the insulation material was cured at $150^{\circ} \mathrm{C}$ during 1 hour after removing the masking.
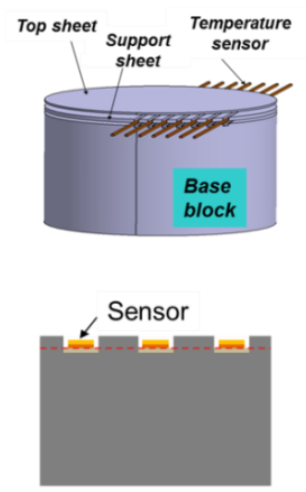

(c) Embedding sensor

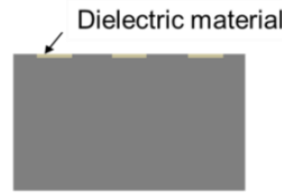

(a) Lower insulation coating

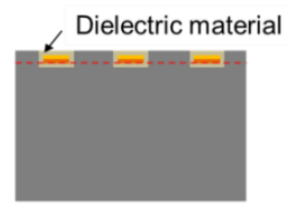

(d) Upper insulation coating

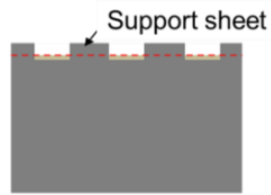

(b) Support sheet install

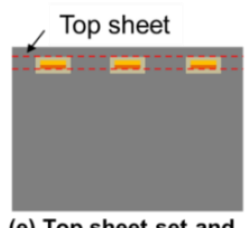

(e) Top sheet set and metal bonding

Fig. 2: Fabrication of embedded temperature sensors array on the thick steel base block.

Next, the insulation material was filled in the slits of support sheet with T/C sensors already installed. Electrical insulation material was cured with same conditions as above. Subsequently, the top sheet was covered on the support sheet. Finally, the embedding of T/C sensors to the steel block was completed by a metal diffusion bonding process. And also, the 
accuracy of embedded sensor position deviation was measured maximum depth of $17 \mu \mathrm{m}$ and horizontal of $190 \mu \mathrm{m}$ with cross section wire cutting. The electrical resistance between steel block and T/C sensors was measured over than $2 \mathrm{k} \Omega$. This result means that the sensors are successfully embedded to the steel block.

\section{Application to Heat Flux Measurement}

\subsection{Experimental Setup for Water Impinging Jet Cooling}

Fig. 3 shows the installed water impinging jet and high frequency heating system. The experimental apparatus consists of an induction heating system, a constant temperature water reservoir, a water pump (CRN 1-15, Grundfos), and electromagnetic flow meter (GF630A/LF600, Toshiba), jet nozzle, the test specimen and a data acquisition system (EX1032A). Also, a commercial $500 \mu \mathrm{m}$ diameter T/C was inserted to $5 \mathrm{~mm}$ depth hole at bottom of the test specimen to measure bottom temperature that would be used for the semi-infinite approximation.

The experimental conditions are shown as Table 1: A height of nozzle from surface of specimen was $100 \mathrm{~mm}$, and an inner diameter of nozzle was $3 \mathrm{~mm}$. The setting flow rate was $0.15 \mathrm{~m} / \mathrm{hr}$, and Reynolds number of this flow rate is 15,000 . And also, the temperature of cooling water was maintained $15^{\circ} \mathrm{C}$. The target temperatures were $600{ }^{\circ} \mathrm{C}$ [3], and 3 specimens were tested. The depth of embedding sensor of specimen A and B were $550 \mu \mathrm{m}$. When the temperature of the test specimen reaches to a saturation of target temperature, the water impinging jet was impinged on the surface of steel block. The temperature histories with time of each position were recorded with a $10 \mathrm{data} / \mathrm{sec}$.

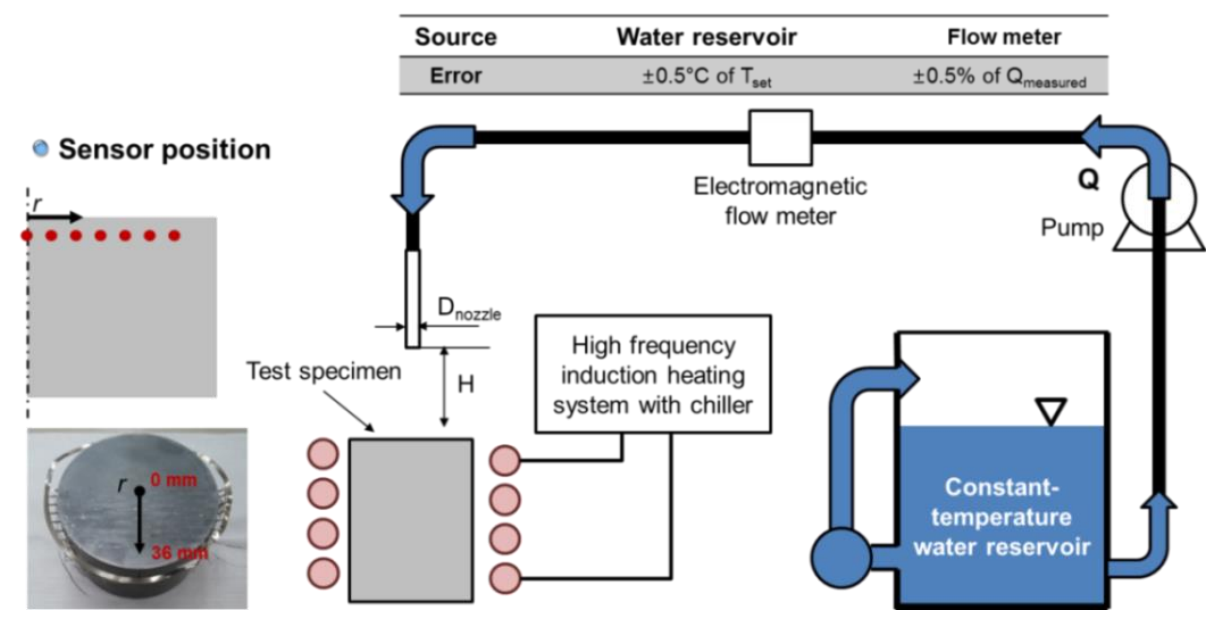

Fig. 3: Experimental setup for water impinging jet cooling.

Table 1: Experimental conditions for water impinging jet cooling.

\begin{tabular}{|c|c|c|c|c|}
\hline $\begin{array}{l}\text { Specimen - } \\
\text { Test number }\end{array}$ & $\begin{array}{c}H, D_{\text {nozzle }} \\
\text { [mm] }\end{array}$ & $\begin{array}{c}Q \\
{\left[\mathrm{~m}^{3} / \mathrm{hr}\right]}\end{array}$ & $\begin{array}{l}\mathbf{T}_{\mathrm{i}}, \mathbf{T}_{\mathrm{w}} \\
{\left[{ }^{\circ} \mathrm{C}\right]}\end{array}$ & $\begin{array}{c}\text { Sampling rate } \\
{[\mathrm{Hz}]}\end{array}$ \\
\hline A-1 & \multirow{2}{*}{100,3} & \multirow{2}{*}{0.15} & \multirow{2}{*}{600,15} & 50 \\
\hline B-1,2,3 & & & & 10 \\
\hline
\end{tabular}

1, 2, 3 mean the repeated experiments

\subsection{Heat Flux Measurement under Water Impinging Jet Cooling Results and Discussions}

The heat flux in each experiment was calculated by using the 1-D transient conduction method as in Eq. (1)[4].

$$
\dot{q}(m \tau)=\frac{2 \sqrt{\rho c k}}{\pi \tau} \sum_{n=0}^{m}\left(T_{n+1}+T_{N-1}-2 T_{n}\right)(m-n)^{\frac{1}{2}}
$$


Fig. 4(a) shows that the heat flux distribution using temperature distribution when the initial temperature of $600^{\circ} \mathrm{C}$. When the initial temperature was $600^{\circ} \mathrm{C}$ in the same test specimen, the deviation of heat flux was generally less than 0.2 $\mathrm{MW} / \mathrm{m}^{2}$ at the all radial positions. It shows the reproducibility of the measurement using the embedded sensor to steel block. The maximum heat flux at the center position of all test specimens was appeared in 0.3 second. However, the maximum heat flux from the $18 \mathrm{~mm}$ radial position in the A-1 test result was reached later than the results using the B specimen.
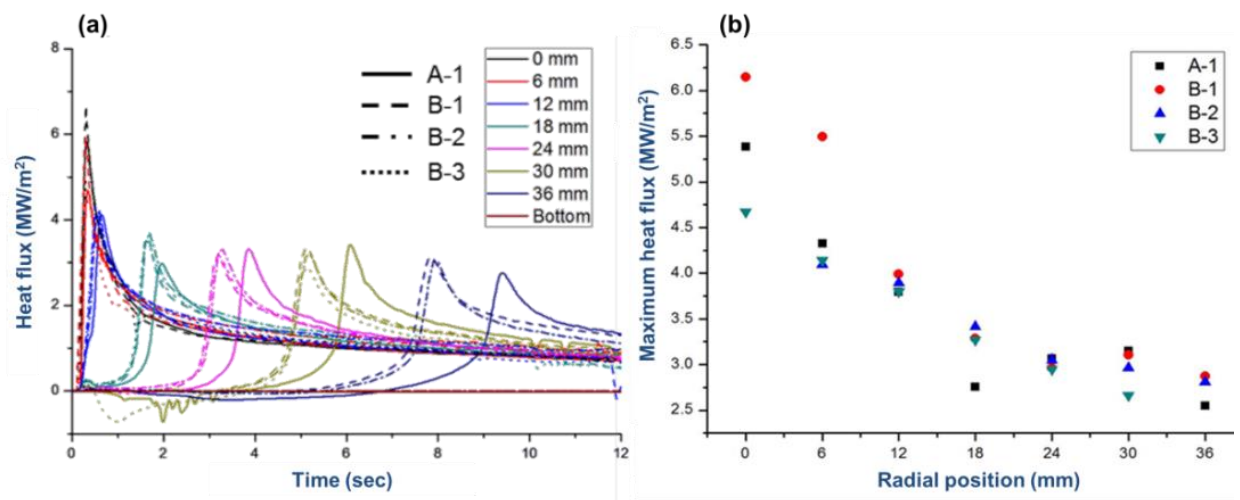

Fig. 4: (a) Heat flux measurement for water impinging jet cooling, (b) Maximum heat flux in each radial position.

\section{Conclusions}

The embedded Thermocouple temperature sensor array in the steel block has been developed to measure the heat flux of water impinging jet cooling on the hot surface. The measurement of the heat flux of the water impinging jet cooling on the hot surface by using the 1-D transient conduction method has been first challenged. Fig. 4(b) illustrates the maximum heat flux in each radial position. It shows that the highest heat flux was appeared at the center position and reduced father from the center. The maximum heat flux was appeared in $6 \mathrm{~mm}$ radial position instead of the center position. The maximum heat flux from the A and B specimens was less than $0.2 \mathrm{MW} / \mathrm{m}^{2}$ at the all radial positions expect the $0,6 \mathrm{~mm}$ as shown in Fig. 4. In the repeated experiments using the B specimen, the maximum heat fluxes were similar too. And also, the effect of horizontal deviation critical heat flux which of the sensor position from the designed position heat flux error is maximum $0.7 \%$ to negligible. It shows that the repeatability and reproducibility of the embedded temperature sensor into SUS block to measure surface heat flux distribution.

\section{Acknowledgements}

This work was supported by the National Research Foundation of Korea (NRF) grant funded by the Korea government (MSIP) (No. 2017R1A2B2006264).

\section{References}

[1] F. P. Incropera, and D. P. DeWitt, Introduction to Heat Transfer. New York: John Wiley \& Sons, 2001.

[2] R. N. Childs, J. R. Greenwood, and C. A. Long, "Heat flux measurement techniques, Proceedings of the Institution of Mechanical Engineers,” Part C: J. Mechanical Engineering Science, vol. 213, no.7, pp. 655-677, 1999.

[3] N. Karwa, T. Gambaryan-Roisman, P. Stephan, and C. Tropea, "Experimental investigation of circular free-surface jet impingement quenching: Transient hydrodynamics and heat transfer," J. Experimental Thermal and Fluid Science, vol. 35, no. 7, pp. 1435-1443, 2011.

[4] M. L. G. Oldfield, T. V. Jones, and D. L. Schultz, "On-Line Computer for Transient Turbine Cascade Instrumentation," J. IEEE Transactions on Aerospace and Electronic Systems, vol. AES-14, no. 5, pp. 738-749, 1978. 